\title{
Ecological civilization: perspectives from landscape ecology and landscape sustainability science
}

\author{
Amy E. Frazier • Brett A. Bryan - Alexander Buyantuev • Liding Chen • \\ Cristian Echeverria $\cdot$ Peng Jia $\cdot$ Lumeng Liu $\cdot$ Qin Li • \\ Zhiyun Ouyang $\cdot$ Jianguo Wu $\cdot$ Wei-Ning Xiang $\cdot$ Jun Yang \\ Lihua Yang $\cdot$ Shuqing Zhao
}

Received: 3 January 2019/Accepted: 8 January 2019/Published online: 6 February 2019

(C) Springer Nature B.V. 2019

Keywords Landscape sustainability science · Eco-civilization · Human well-being ·

Forest landscape restoration

Reversing ecological degradation is critical for survival of many species but will not occur without a

In June 2018, the authors joined the 6th Forum of Landscape Sustainability Science in Beijing, China with the goal of inspiring the next generation of landscape ecologists to work toward a more sustainable future. This editorial represents the outcome of a discussion on ecological civilization and the role that landscape ecology and landscape sustainability science may play in helping achieve that and other related goals.

A. E. Frazier $(\bowtie)$.

School of Geographical Sciences and Urban Planning, Arizona State University, Tempe, AZ 85281, USA e-mail: Amy.Frazier@asu.edu

\section{B. A. Bryan}

School of Life and Environmental Sciences, Deakin University, Melbourne, Australia

\section{A. Buyantuev}

Department of Geography and Planning, University at Albany, State University of New York, Albany, NY 12222, USA

L. Chen

State Key Laboratory of Urban and Regional Ecology, Research Center for Eco-Environmental Sciences,

Chinese Academy of Science, Beijing, China transformational reduction in humanity's environmental impact. Ecological civilization is a way of approaching social and ecological reform and represents a new standard of human existence that may be sustainable well into the future. However, how to achieve ecological civilization still remains a question. Landscape sustainability science, with its theoretical basis in sustainability science and landscape ecology, offers a decisive path for achieving an ecological civilization. Three concepts integral to landscape ecology will be essential for contributing to an ecological civilization: (1) linking landscape patterns with biodiversity and ecosystem processes/function across scales, (2) measuring

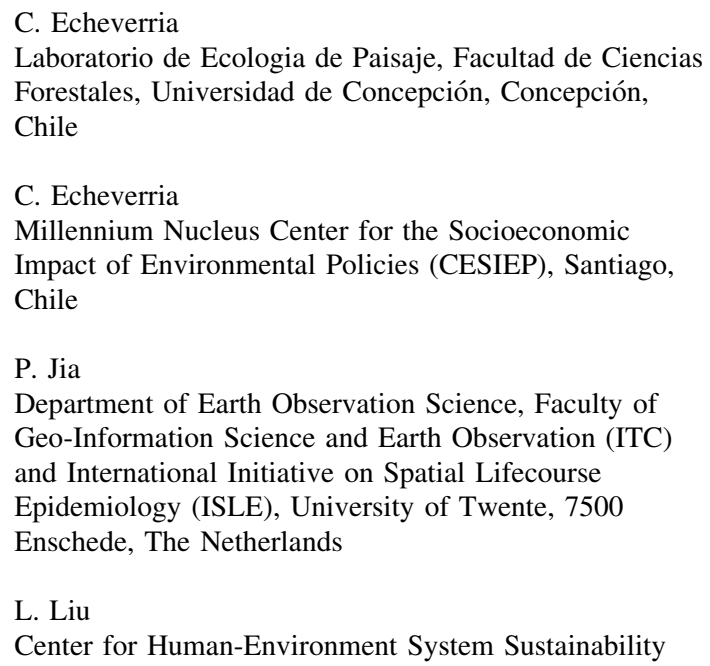


connectivity and flows across spatially heterogeneous systems, and (3) a systems understanding of the linkages between disturbance, resilience, and recovery. Achieving an ecological civilization is within the scope of human capability, but it will require a fundamental shift in world view and cooperation amongst all actors in the human race. A key place to start is with landscapes. This editorial provides perspectives from landscape ecology and landscape sustainability science for achieving this goal.

\section{Introduction}

The Anthropocene epoch marks a fundamental change in the relationship between humans and nature (Heurtebise 2017). Human manipulation and degradation of the environment has reached the point that cumulative global impacts are not only affecting our food, fiber, and water systems but also threatening people's health and well-being (Whitmee et al. 2015). The October 2018 report from the Intergovernmental Panel on Climate Change (IPCC) warns that we risk catastrophic environmental breakdown if global warming is not kept to a maximum of $1.5^{\circ} \mathrm{C}$ (IPCC 2018). Reversing climate change and other forms of ecological degradation is critical for the survival of many species, including humans (Magdoff 2011), but it will not occur without a transformational reduction in humanity's environmental impact.

Some societies have already begun reconsidering their relationship with nature and recognizing that drastic changes to protect our ecological systems are

(CHESS), State Key Laboratory of Earth Surface Processes and Resource Ecology (ESPRE), Faculty of Geographical Science, Beijing Normal University, 100875 Beijing, China

Q. Li

Institute of Biodiversity Science, Fudan University, Shanghai, China

\section{Q. Li}

Jiangxi Province Key Laboratory of Watershed Ecosystem Change and Biodiversity, Center for Watershed Ecology, Institute of Life Science, Nanchang University, Nanchang, China

Z. Ouyang

Research Center for Eco-Environmental Sciences, Chinese Academy of Sciences, Beijing, China necessary to ensure the long-term health and wellbeing of humans. This new way of approaching social and ecological reform has been termed 'ecological civilization' and represents a new standard of human existence that may be sustainable well into the future (Gare 2012; Heurtebise 2017). Ecological civilization is founded on ecological principles but also requires integrated societal reforms including economic, political, demographic, and educational transformations (Magdoff 2011; Wang 2013; Wang et al. 2014). It is a lofty goal to reform society, but given the grim trajectories forecast for climate change and other ecosystem services, it may represent our best hope for a sustainable global society.

\section{What is ecological civilization?}

In its simplest form, ecological civilization is a dynamic equilibrium state where humans and nature interact and function harmoniously. The concept of an 'ecological culture' is believed to have been put forth by a biologist in the former Soviet Union in the 1980s (Gare 2012), but the concept did not see widespread practical use until the mid-2000s when the term 'ecological civilization' was translated and adopted by the Communist Party of China as an explicit goal. Since then, China has embraced the concept with vigor, notably as a central policy objective mentioned at several national congresses of the Chinese Communist Party and written into China's "13th Five-year Plan" (2016-2020), which promotes the development of ecological civilization.

J. $\mathrm{Wu}$

School of Life Sciences, School of Sustainability, Julie A. Wrigley Global Institute of Sustainability, Arizona State University, Tempe, AZ, USA

J. Wu

Center for Human-Environment System Sustainability (CHESS), Beijing Normal University, Beijing, China

W.-N. Xiang

Department of Geography and Earth Sciences, University of North Carolina - Charlotte, Charlotte, NC, USA

J. Yang

Ministry of Education Key Laboratory for Earth System Modeling, Department of Earth System Science, Tsinghua University, Beijing, China 


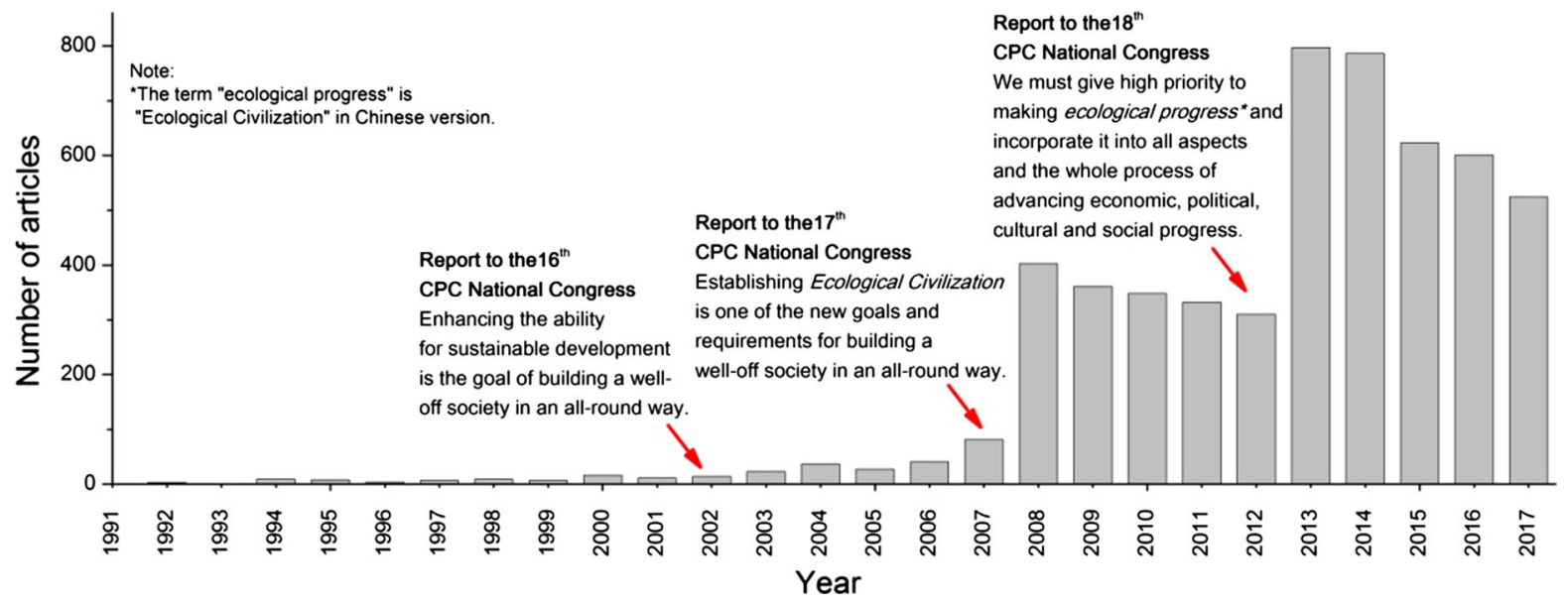

Fig. 1 Publications on ecological civilization in Chinese core journals and main statements in several reports of National Congress of the Communist Party of China (CPC). Papers that

While the term 'ecological civilization' and its abridgement 'eco-civilization' have appeared in many Chinese State Reports and scientific publications over the last several decades (Fig. 1), the fundamental concept of humans co-existing with nature is not new in China. Indeed, the word "unity of human and nature" (天人合一, in Chinese) dates back thousands of years and forms the core concept of several traditional Chinese religions including Taoism, Confucianism, and Buddhism. The term embodies a long-held philosophy and guiding principle of achieving harmony and balance in personal and social development. Therefore, the emergence of an ecological civilization in China is not necessarily the creation of entirely new concepts, vocabularies, and attitudes but rather the reaffirmation of long-held, traditional values (Slovic 2012).

While there are multiple perspectives through which ecological civilization can be viewed (e.g., values, culture, institutions, actions), above all, achieving ecological civilization requires a

L. Yang

School of Government, Peking University, Beijing, China

L. Yang

School of Public Administration, Beihang University, Beijing, China

S. Zhao

College of Urban and Environmental Sciences, Peking

University, Beijing, China contain '生态文明 (ecological civilization)' in their titles, abstracts, or keywords were searched in the China Knowledge Resource Integrated Database on 19 November 2018

fundamental shift in world view from the prevailing belief that humans must exhibit dominance over nature to a more eco-centric view where humans are simply one component of a larger system. Environmental democracy, where humans are equal to all forms of life (and non-living components) on Earth with rights and responsibilities to both exploit and protect the environment, is therefore an integral component of ecological civilization (Morrison 1995). In other words, humans must play an active role in managing their relationship with nature. Currently, human appropriation of natural capital exceeds the regenerative capacity of the Earth's life support systems (Rockström et al. 2009), creating an unsustainable situation for our landscapes. If we are to reverse the degradation occurring in ecosystems across the globe, specifically with respect to climate change and biosphere integrity (Steffen et al. 2015), humans will need to learn to meet their immediate needs in a more balanced way that ensures the maintenance of the Earth's life-support functions to provide goods and services in the long term.

The question then becomes, how do we achieve ecological civilization? And what tools can landscape ecology and landscape sustainability science offer toward that goal? 


\section{Contributions from landscape ecology and landscape sustainability science}

Achieving ecological civilization is an extremely broad goal and involves addressing a range of human-environment issues including, but not limited to: air, water, and soil pollution; remediation of contaminated areas; clean energy; climate change mitigation; food security; ecosystem health; sustainable land use; human welfare; and social justice and equity. No single field or discipline is positioned to offer a panacea of solutions or methods to address all these issues. However, certain core concepts in landscape ecology and landscape sustainability science, such as linking landscape patterns with biodiversity and ecosystem processes across scales, measuring connectivity and flows across spatially heterogeneous systems, and a spatial systems understanding, are all essential for implementing ecological civilization on the ground. We argue that ecological civilization cannot be achieved at any scale without properly managing the composition and configuration of our landscapes and balancing conservation with development in geopolitical regions. In the inaugural issue of the journal Landscape Ecology, the editor-in-chief Frank Golley (1987) established that "the task of correcting biospheric disorder is a universal activity, requiring information and insight from all. We intend that Landscape Ecology have this broad objective and that it be relevant to the problems that face mankind..." Twenty years later, in 2007, the current editor-inchief, Jianguo (Jingle) Wu reaffirmed that "the most salient and unambiguous goal of Landscape Ecology, since day one, has been to promote interdisciplinary and integrative studies of landscapes, especially on broad scales, not only to improve our understanding of the world of landscapes, but also to provide solutions to the plethora of problems occurring in our landscapes (Wu 2007a, p. 1433)."

Within the framework of landscape studies, any ecological civilization will certainly be embedded in a landscape where the biophysical elements must have the capacity to meet current and future human needs. We highlight three concepts integral to landscape ecology that will be essential for contributing to an ecological civilization: (1) linking landscape patterns with biodiversity and ecosystem processes/function across scales, (2) measuring connectivity and flows across spatially heterogeneous systems, and (3) a systems understanding of the linkages between disturbance, resilience, and recovery.

Relationships between landscape patterns and (eco)system function

Landscape ecology is predicated on the assumption that spatial patterns influence ecological processes, and those processes, in turn, feedback to form and alter landscape patterns. A cornerstone of understanding these relationships is the quantification of spatial patterns using landscape metrics derived from remote sensing and geographic information systems (GIS) data, with key insights gained in the past decades (Gustafson 2019). However, while the focus in landscape ecology has had a prominent emphasis on ecosystem processes and functioning (but see Naveh and Lieberman 1984), there is growing recognition that land systems (and therefore landscapes) are coupled human-natural systems. During the past 30 years, landscape ecology has increasingly adopted a more holistic, social-ecological approach to understanding the relationship between pattern and process (Wu 2017).

One way in which this holistic approach is occurring is through the adaptation of landscape metrics to measure social ecosystem service areas. For example, De Vreese et al. (2016) demonstrated how social landscape metrics measuring abundance, diversity, richness, risk, and rarity of ecosystem services can be used to capture and integrate social perspectives into landscape analyses. While debates will continue around the relevance of these pattern metrics, and, more generally, the models used to compute them (Frazier and Kedron 2017), the reality is that monitoring global changes that affect and are affected by an ecological civilization requires broadscale Earth observation. The tools and techniques from landscape ecology are critical for this task.

Measuring connectivity and flows across spatially explicit systems

The central tenet of landscape ecology - that landscape patterns and ecological processes are intertwined-means that landscape ecologists have a long tradition of measuring connectivity (through 
spatial pattern metrics) and energy flows across landscapes. Recent research highlights the need to connect ecosystem services with beneficiaries (Bagstad et al. 2013), which will prove critical in an ecological civilization. However, as related to the points above, the integration of social aspects into landscape-wide studies is critical. Specifically, political and administrative boundaries often serve as barriers that constrain environmental flows (e.g., walls and fences prevent animal movement), but they also prevent the unrestrained flow of practices and ideas and may ultimately set the spatial extent for social and cultural analyses of ecological civilization practices. Studies of ecological civilization will almost certainly compound the search for appropriate observation, experimental, modeling, and policy scales (Wu 2007b), which is also central to landscape ecology.

A systems approach to disturbance, resilience, and recovery

Landscape ecologists take a holistic view of the interactions between landscape elements, the ecological system, and organisms - both human and nonhuman. Furthermore, the field is concerned with how these integrated systems are influenced by human interventions. Perhaps the most salient example of this systems approach is through landscape ecological work related to disturbance, resilience, and recovery (e.g., Turner et al. 2013). In her Robert H. MacArthur award lecture titled "Disturbance and landscape dynamics in a changing world," Turner (2010) stressed that the effects of disturbances can persist for decades or centuries. Furthermore, research has shown that systems may not be resilient to novel disturbances, despite a record of past resilience. Looking to the future, landscape ecologists have already begun to focus on reducing vulnerable populations, examining the relationships between anthropogenic land cover change and disturbance patterns, and asking how disturbances will interact with climate changes and feedback to global cycles.

While disturbances have traditionally been defined as relatively discrete events (e.g., several hours to several weeks) (Turner et al. 2001), 'slow onset disasters' such as drought, climate change, desertification, and environmental degradation, also disrupt ecosystems, populations (both human and ecological), and communities. Human-induced climate change may already be the largest planetary disturbance ever orchestrated by humans, and any ecological civilization will be embedded in a system where the effects of climate change will be present. How long these effects will persist and whether or not they can be reversed over time is yet to be seen. However, the foundational understanding of disturbances gained through a systems landscape ecology approach will be critical.

\section{The role of landscape sustainability science}

Landscape sustainability science (LSS) focuses on improving the dynamic relationship between ecosystem services and human well-being in changing social, economic, and environmental conditions ( $\mathrm{Wu}$ 2013, p.1015). LSS shares many commonalities with ecological civilization. Both are rooted in reflection on the relationship between environment and development; both share a goal of balancing economic and social development with natural resources and ecosystem services; and both face similar challenges in terms of execution, financing, and capacity. However, LSS, with its theoretical basis in sustainability science and landscape ecology, offers a decisive path for achieving an ecological civilization. LSS and landscape ecology are closely related through a shared focus on ecosystem services (Fig. 2). For example, one of the central questions of LSS is how landscape pattern affects the long-term understanding and maintenance of the relationships between landscapes and human well-being via ecosystem service provision. To achieve an ecological civilization, it is vital to respond to such questions while having a clear understanding of the reciprocal link between them.

To achieve this new level of civilization, we first need a deeper understanding of how to design and manage sustainable landscapes that provide longterm ecosystem services essential for human wellbeing. For this purpose, LSS emphasizes the need to identify landscape-specific ecosystem services essential for human well-being. Specifically, Wu (2013) 


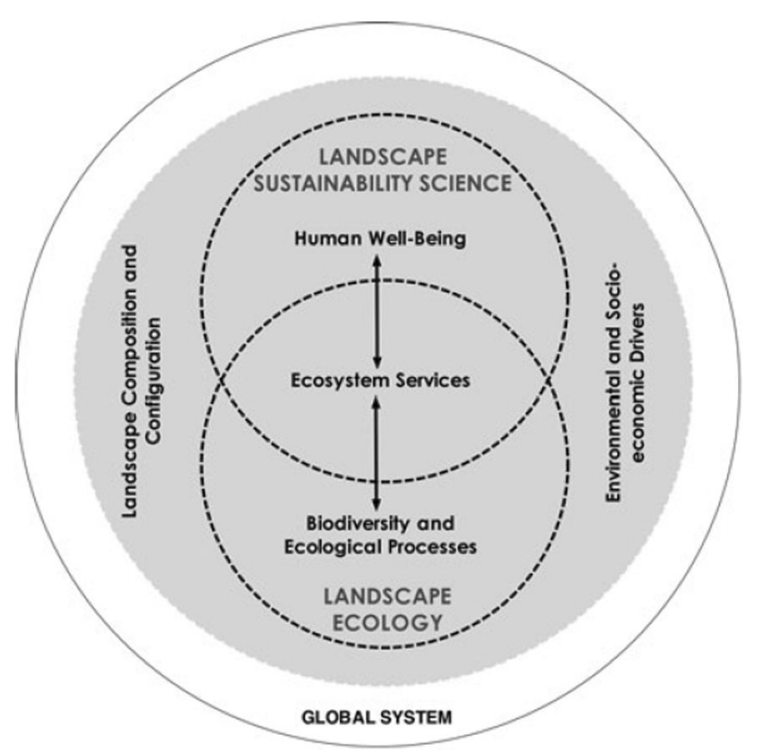

Fig. 2 Relationship between landscape sustainability science and landscape ecology (from Wu 2013)

addresses four basic questions: "what is to be sustained, what is to be developed, how are these two aspects related to each other, and on what scales should all these be considered?" With the goal of achieving an ecological civilization, we should also be asking ourselves: what is to be restored? Yet, before degraded landscapes can offer such spaces, it will be imperative for society to identify the key elements that need improving.

The concept of forest landscape restoration offers an example of how LSS can provide a path to ecocivilization. Forest landscape restoration is a planned process aimed at recovering ecological functionality while simultaneously enhancing human well-being at the landscape level (Mansourian et al. 2005; Maginnis et al. 2007). The process is focused on recovering the capacity of the entire landscape-not just a habitat or ecosystem-from a holistic perspective, which embodies the close interrelationships between the components of LSS, such as biodiversity, ecosystem processes, ecosystem services and human wellbeing. Additionally, forest landscape restoration seeks to redefine the relationship between human and nature by implementing innovative practices aimed at restoring ecological and socio-economic processes that benefit local community and stakeholder groups. As such, forest landscape restoration provides a model for the process needed to help society move toward ecological civilization.

\section{Areas for measurable success}

Human well-being is a key focus of LSS and one where we can measure progress toward an ecological civilization. One of the most salient features that characterize human civilization during the past millennium is accelerating urbanization (Wu et al. 2014), which is impacting human well-being in varied ways (Yang et al. 2018). Wu (2014) points out that human well-being depends fundamentally on ecosystem services, requiring concerted ecological, economic, and social actions in response to changes within and beyond our landscapes. Specifically, measuring improvements to human health across landscapes can be an indicator of the sustainable balance between human needs and nature. Of the 17 United Nations' Sustainable Development Goals, Goal \#3 'Good Health and Well-Being' requires balancing environmental protection (Goals 6, 7, 11, 12, 13, 14, 15) with social and economic growth (Goals 1, 4, 5, 9,10 ), and thus encapsulates many of the most important building blocks for an ecological civilization. The past two decades have seen a rapid increase of studies associating landscape patterns with human health and disease spreading, leading to new research areas known as geohealth (Dummer 2008), landscape epidemiology (e.g., Cumming et al. 2015), and spatial lifecourse epidemiology (Jia 2019). A number of broad-scale studies have demonstrated the success of applying spatial technologies, such as GIS, remote sensing, and landscape modeling, to aid in achieving the Millennium Development Goals and Sustainable Development Goals (Jia et al. 2016; Gao and Bryan 2017) and human and planetary health (Bohnet et al. 2011; Jia et al. 2015; Whitmee et al. 2015; Jia and Stein 2017; Opdam et al. 2018; Sun et al. 2018).

Bryan et al. (2018) synthesized China's efforts over the past 20 years to arrest and reverse an accelerating decline in the environmental and economic sustainability of its rural environments. Through a portfolio of major programs, China's central government invested over US $\$ 350$ billion in implementing sustainability intervention across nearly two-thirds of China's land area. The programs were successful in reducing poverty and hunger, deforestation, soil erosion and sedimentation, desertification and dust storms, and biodiversity decline, and realigning China's rural areas on a path more consistent with ecological civilization. A key part of 
the success of this massive intervention was an evidence-based, targeted, coordinated, and integrated approach at-scale, which anticipated the trade-offs that are common in land systems. For example, interventions were aimed at breaking the poverty and environmental degradation trap-a vicious cycle where increasing poor people apply more and more pressure on the local environment to produce food and income, which degrades the environment further and, makes them poorer still. As another example, reducing deforestation and reforesting large areas of land minimized the impact on timber supply and agricultural production through parallel and complementary programs aimed at boosting timber supply and food production. China's sustainability programs implemented many principles that we now recognize as part of landscape ecology, systems dynamics, and sustainability science.

\section{Concluding remarks}

History has witnessed the progression of human development from primitive civilizations to agrarian societies to the eventual transition into industrial civilizations. As countries compete to achieve higher and higher levels of prosperity at the cost of the environment, the concept of ecological civilization provides a timely wake-up call. Reversing the trends of industrial civilizations and rolling back the clock on environmental degradation through processes such as forest and grassland landscape restoration will continue to provide measures of a successful transition to ecological civilization.

Implementing this concept will not be an easy task though and will require fundamental changes across society. In addition to shifting values and cultures, there must be action at the organizational and institutional levels to promote these shifting ideas allowing them to be realized through formal and informal institutional arrangements. As such, achieving an ecological civilization is a long-term and bold goal for human social development, and there is a long way to go before we realize such a society. First, humans' role in the earth ecosystem need to be reestablished and activities need to be reconsidered from the standpoint of integral ecosystem management. Second, individuals will need to redefine personal behaviors with respect to conservation and environmental protection. Third, working toward an ecological civilization requires input and involvement from all corners of society including economic, cultural, political, religious, environmental, etc. Achieving an ecological civilization is within the scope of human capability, but it will require a fundamental shift in world view and cooperation amongst all actors in the human race. We need to start with our landscapes!

\section{References}

Bagstad KJ, Johnson GW, Voigt B, Villa F (2013) Spatial dynamics of ecosystem service flows: a comprehensive approach to quantifying actual services. Ecosyst Serv $4: 117-125$

Bohnet I, Roebeling P, Williams K, Holzworth D, van Grieken M, Pert P, Kroon F, Westcott D, Brodie J (2011) Landscapes toolkit: an integrated modelling framework to assist stakeholders in exploring options for sustainable landscape development. Landscape Ecol 26(8):1179-1198

Bryan BA, Gao L, Ye Y, Sun X, Connor JD, Crossman ND, Stafford Smith M, Wu J, He C, Yu D, Liu Z, Li A, Huang Q, Ren H, Deng X, Zheng H, Niu J, Han G, Hou X (2018) China's response to a national land system sustainability emergency. Nature 559:193-204

Cumming G, Abolnik C, Caron A, Gaidet N, Grewar J, Hellard E, Henry DW, Reynolds C (2015) A social-ecological approach to landscape epidemiology: geographic variation and avian influenza. Landscape Ecol 30(6):963-985

De Vreesea R, Leys M, Fontaine CM, Dendoncker N (2016) Social mapping of perceived ecosystem services supply The role of social landscape metrics and social hotspots for integrated ecosystem services assessment, landscape planning and management. Ecol Indic 66:517-533

Dummer TJB (2008) Health geography: supporting public health policy and planning. Can Med Assoc J 178 (9): 1177-1180

Frazier AE, Kedron P (2017) Landscape metrics: past progress and future directions. Curr Landsc Ecol Rep 2(3):63-72

Gao L, Bryan BA (2017) Finding pathways to national-scale land-sector sustainability. Nature 544(7649):217-222

Gare A (2012) China and the struggle for ecological civilization. Capital Nat Social 23(4):10-26

Golley FB (1987) Introducing landscape ecology. Landscape Ecol 1:1-3

Gustafson E (2019) How has the state-of-the-art for quantification of landscape pattern advanced in the twenty-first century? Landscape Ecol. https://doi.org/10.1007/s10980018-0709-X

Heurtebise JY (2017) Sustainability and ecological civilization in the age of Anthropocene: an epistemological analysis of the psychosocial and "culturalist" interpretations of global environmental risks. Sustainability 9:1331 
IPCC (Intergovernmental Panel on Climate Change) (2018) Global Warming of $1.5^{\circ} \mathrm{C}$ : an IPCC special report on the impacts of global warming of $1.5^{\circ} \mathrm{C}$ above pre-industrial levels and related global greenhouse gas emission pathways, in the context of strengthening the global response to the threat of climate change, sustainable development, and efforts to eradicate poverty. http://www.ipcc.ch/re port/sr15/. Accessed 31 Oct 2018

Jia P (2019) Spatial lifecourse epidemiology, Lancet Planet Health 3(2) (in press)

Jia P, Anderson JD, Leitner M, Rheingans R (2016) Highresolution spatial distribution and estimation of access to improved sanitation in Kenya. PLoS ONE 11(7): e0158490

Jia P, Sankoh O, Tatem AJ (2015) Mapping the environmental and socioeconomic coverage of the INDEPTH international health and demographic surveillance system network. Health Place 36:88-96

Jia P, Stein A (2017) Using remote sensing technology to measure environmental determinants of non-communicable diseases. Int J Epidemiol 46(4):1343-1344

Magdoff F (2011) Ecological civilization. Mon Rev 62(8):1-25

Maginnis S, Rietbergen-McCracken J, Jackson W (2007) Introduction. In: Rietbergen- McCracken J, Maginnis S, Sarre A (eds) The forest landscape restoration hand- book. Earthscan, London, pp 1-4

Mansourian S, Vallauri D, Dudley N (2005) Forest restoration in landscapes: beyond planting trees. Springer, New York

Morrison R (1995) Ecological democracy. South End Press, Boston

Naveh Z, Lieberman AS (1984) Landscape ecology: theory and application. Springer-Verlag, New York

Opdam P, Luque S, Nassauer J, Verburg PH, Wu JG (2018) How can landscape ecology contribute to sustainability science? Landscape Ecol 33(1):1-7

Rockström J, Steffen W, Noone K et al (2009) A safe operating space for humanity. Nature 461:472-475

Slovic S (2012) Landmarks in Chinese ecocriticism and environmental literature: the emergence of a new ecological civilization; social sciences in China Today, http://www. csstoday.com/Item/268.aspx. Accessed 16 Sept 2018

Steffen W, Richardson K, Rockström J, Cornell SE, Fetzer I, Bennett EM, Biggs R, Carpenter SR, De Vries W, De Wit CA, Folke C, Gerten D, Heinke J, Mace GM, Persson LM, Ramanathan V, Reyers B, Sörlin S (2015) Planetary boundaries: Guiding human development on a changing planet. Science 347(6223):1259855

Sun XF, Gao L, Ren H, Ye YQ, Li A, Stafford-Smith M, Connor JD, Wu JG, Bryan BA (2018) China's progress towards sustainable land development and ecological civilization. Landscape Ecol 33(10):1647-1653

Turner MG (2010) Disturbance and landscape dynamics in a changing world. Ecology 91(10):2833-2849

Turner MG, Donato DC, Romme WH (2013) Consequences of spatial heterogeneity for ecosystem services in changing forest landscapes: priorities for future research. Landscape Ecol 28(6):1081-1097

Turner MG, Gardner RH, O'Neill RV (2001) Landscape ecology in theory and practice: pattern and process. Springer-Verlag, New York

Wang R-S (2013) Integrating ecological civilization into social-economic development. Acta Ecol Sin 33(1):1-11

Wang ZH, He HL, Fan MJ (2014) The ecological civilization debate in China: the role of ecological Marxism and constructive postmodernism-beyond the predicament of legislation. Mon Rev 66(6):37-59

Whitmee S, Haines A, Beyrer C, Boltz F, Capon AG, de Souza Dias BF, Horton R (2015) Safeguarding human health in the Anthropocene epoch: report of The Rockefeller Foundation-Lancet Commission on planetary health. Lancet 386(10007):1973-2028

Wu J (2007a) Past, present and future of landscape ecology. Landscape Ecol 22:1433-1435

Wu J (2007b) Scale and scaling: a cross-disciplinary perspective. In: Wu J, Hobbs R (eds) Key topic in landscape ecology. Cambridge University Press, Cambridge, pp 115-142

Wu J (2013) Landscape sustainability science: ecosystem services and human well-being in changing landscapes. Landscape Ecol 28:999-1023

Wu J (2014) Urban ecology and sustainability: the state-of-thescience and future directions. Landsc Urban Plan 125:209-221

Wu J (2017) Thirty years of landscape ecology (1987-2017): retrospects and prospects. Landscape Ecol 32(12):22252239

Wu J, Xiang W-N, Zhao J (2014) Urban ecology in China: historical developments and future directions. Landsc Urban Plan 125:222-233

Yang J, Siri JG, Remais JV et al (2018) The Tsinghua-Lancet Commission on Healthy Cities in China: unlocking the power of cities for a healthy China. Lancet 391 (10135):2140-2184

\section{Publisher's Note}

Springer Nature remains neutral with regard to jurisdictional claims in published maps and institutional affiliations. 